\title{
Predicting an Outcome Less Probable yet More Desirable than the Other Youngjin Kang
}

Department of Psychology, New Mexico State University, Las Cruces, New Mexico

\section{KEYWORDS}

cognitive effort

choice-making

binary-choice

binary-prediction

urn model

probability-matching

optimistic bias
Extant research suggests that the desirability of an outcome influences the way an individual makes a prediction. The current research investigated how an outcome's desirability influences the extent to which an individual evaluates its probability when making a prediction. Two studies were conducted using a single binary prediction based on the urn model. Individuals predicted which color-red or blue-a ball drawn from a bag would be, while being aware of the proportion of each color in the bag. The results of the first study indicated that individuals predicted the more probable outcome regardless of the probabilities of two outcomes. However, when the less probable outcome was more desirable, the proportion of predictions became significantly correlated and better calibrated to the actual probability. This result was interpreted as showing that, when motivated to predict the more desirable but less probable outcome, individuals evaluate its probability more effortfully. This interpretation was tested in the second study. When the probabi ity- matching motivation was implemented, the proportion of individuals who predicted the less probable outcome increased significantly. However, when the less probable outcome was more desirable, the same motivation did not significantly increase the proportion of such individuals. Taken together, these results imply that individuals likely process the same probability informatio differently based on whether this information is useful for predicting a desirable outcome.

\section{INTRODUCTION}

When people make a judgement, they often utilize a fast and frugal strategy - relying on proximal and simple clues rather than expending additional effort to seek out less accessible evidence or information (Gigerenzer \& Goldstein, 1996; Goldstein \& Gigerenzer, 2002). Cognitive effort can be defined as "goal-directed mental exertion" (Sullivan-Toole, Dobryakova, DePasque, \& Tricomi, 2018, p. 2), and research has found that, in general, people find cognitive effort aversive and often avoid being engaged in it (Dunn, Lutes, \& Risko, 2016; Gold et al., 2015; Kool, McGuire, Rosen, \& Botvinick; 2010). Based on the framework of effort-reward trade-off, additional cognitive effort is likely to be exerted only when an individual perceives the effort to be less costly than resultant reward (i.e., the reward linked to the effort outweighs its costs, Kool, et al., 2010; Kool \& Botvinick, 2014; Westbrook \& Braver, 2015). Researchers have found some particular conditions or variables potentially influencing the extent to which one's cognitive effort is exerted: perceived usefulness of information (Hilbig, Michalkiewicz, Castela, Pohl, \& Erdfelder, 2015), increase of reward (Schmidt, Lebreton, Cléry-Melin, Daunizeau, \& Pessiglione, 2012), effort enhancement effect (Lallement, et al., 2014), average reward Corresponding author: Youngjin Kang, Department of Psychology, New Mexico State University, Las Cruces, New Mexico, 88003.

e-mail:yjk@nmsu.edu, 
rate per time (Otto \& Daw, 2018); one's interest in effortful activities (Chevalier, 2018), and one's mood and perception of competence (Efklides, Kourkoulou, Mitsiou, \& Ziliaskopoulou, 2006).

People often overestimate the likelihood of experiencing desirable outcomes but underestimate the likelihood of experiencing undesirable ones (Shepperd, Carroll, Grace, \& Terry, 2002; Weinstein \& Klein, 1996). This psychological phenomenon is termed the optimistic bias (Weinstein, 1980) or the desirability effect (Bar-Hillel \& Budescu, 1995). People often underestimate the probability of their own risks in contexts such as: AIDS (Harris \& Middleton, 1994), lung cancer (Williams \& Clarke, 1997), heart attack (Hoorens \& Buunk, 1993), criminal victimization (Weinstein, 1980), divorce (Fowers, Lyons, \& Montel, 1996), and car accidents (McKenna, 1993). Research suggests several psycho-emotional motivations underlying optimistic bias: self-enhancement (Hoorens, 1993), projecting a positive social-image (Shepperd, et al., 2002, p. 4), control motivation (e.g., the illusion of control; Harris, 1996; Klein \& Helweg- Larsen, 2002; Langer, \& Roth, 1975), and affective reward (Lench, 2009; Loewenstein, Weber, Hsee, \& Welch, 2001; Weinstein, 1980). There are, however, comparatively fewer focused investigations identifying how optimistic bias is cognitively executed (for cognitive processes of optimistic bias, see Brown, 1986; Hoorens, 1993; Krizan \& Windschitl, 2007; Shepperd, et al., 2002). One notable cognitive process that could lead to optimistic bias is selective (cognitive) focus (Gerrard, Gibbons, \& Warner, 1991; Marks \& Duval, 1991; Ross, Greene, \& House, 1977). For example, people mainly seek out favorable information or evidence, while essentially ignoring others (Gouveia \& Clarke, 2001; Kahneman \& Tversky, 1979a; Klar \& Giladi, 1997; Klar, Medding \& Sarel, 1996). However, in cases where favorable information is not easily available, additional effort becomes necessary for seeking out favorable information (Krizan \& Windschitl, 2007). Researchers have identified that unfavorable information could enhance one's cognitive effort in a self-serving manner-seeking out favorable information in order to undermine the validity of the unfavorable information (Ditto \& Lopez, 1992; Ditto, Scepansky, Munro, Apanovitch, \& Lockhart, 1998).

The current research suggests that cognitive effort can also be exerted when an individual is motivated to predict a desirable outcome, thus gaining affective reward. Specifically, the current research used the paradigm of binary prediction based on the urn model, in which one outcome was more desirable than the other, thus motivating individuals to predict the more desirable one (Bar-Hillel \& Budescu, 1995; Lench, 2009; Krizan \& Windschitl, 2007). Additionally, by making the more desirable outcome less probable, individuals were manipulated to be motivated to search for new evidence or information beyond the simplest criterion of one outcome being more probable than the other (Busemeyer \& Townsend, 1993; Friedman \& Massaro, 1998). The fast and frugal strategy, by which one predicts whichever outcome is more probable, can be applied to any combination of the probabilities between two outcomes (e.g., $90 \%$ and $10 \%$ vs. $60 \%$ and $40 \%$ ). However, when a more desirable outcome is less probable, this fast and frugal strategy becomes more difficult to apply. Therefore, the binary prediction in which one future outcome is less probable yet more desirable could work as a condition where individuals search for evidence or information that was less accessible initially. One possible aspect of the information that is useful for predicting a less probable outcome could be the stochastic nature of the outcome-the expectation that a less probable outcome would occur by chance (e.g., probability-matching; Gal, 1996; James \& Koehler, 2011; Newell \& Rakow, 2007). In general, understanding the stochastic nature of an outcome demands complex thought processes (Fischbein, Nello, \& Marino, 1991; Jones, Langrall, \& Mooney, 2007; Nilsson, 2013; Piaget \& Inhelder, 1975) and less immediate information (Kahneman \& Tversky, 1982, p.153).

In the current research, the aforementioned concepts: binary choice, cognitive effort, optimistic bias, and probability information were synthesized to formulate the hypothesis tested in Study 1, summarized as follows: When making a binary choice, individuals often use a simple criterion without expending further cognitive effort. Not only is selective (cognitive) focus utilized for an optimistic prediction, but cognitive effort could also become necessary for it if supportive information is initially less accessible. When one of two future outcomes is more desirable than the other, individuals are motivated to predict the more desirable outcome. However, if this desirable outcome is less probable, individuals have more difficulty employing the simplest criterion of one outcome being more probable than the other. Finally, it was hypothesized that, under such a condition-that is, individuals expending extra cognitive effort to seek out other supportive evidence or information-the probability of a less probable, yet more desirable outcome could be evaluated more effortfully. Study 1 experimentally demonstrated the phenomenon pertaining to this hypothesis and Study 2 tested the validity of the cognitive process assumed to be embedded in this phenomenon.

\section{STUDY 1}

Study 1 demonstrated the phenomenon pertaining to the hypothesis explained in the previous section by applying a single binary prediction based on the urn model. Specifically, while being informed of the specific proportion between the two colors of balls (red or blue) in a bag, individuals made a prediction as to the color of ball that would be drawn from the bag. The pattern of prediction made by multiple individuals was examined as a function of different proportions between the two colors. Specifically, the proportion of the predictions between the two colors was compared to their corresponding actual proportion by using the graph based on probability weighing function (see Kahneman \& Tversky, 1979b; Tversky \& Kahneman, 1986). Subsequently, the first prompt was modified such that drawing a red ball was more desirable. For the analyses, the four conditions were categorized based on probability and desirability of an outcome, as follows.

- Condition 1: Drawing a red ball is less probable than drawing a blue ball.

- Condition 2: Drawing a red ball is more probable than drawing a blue ball. 
- Condition 3: Drawing a red ball is less probable but more desirable than drawing a blue ball.

- Condition 4: Drawing a red ball is more probable and more desirable than drawing a blue ball.

When predicting the color of a ball that will be drawn from a bag containing a specific proportion of red and blue balls, it was expected that individuals would use the simplest criterion based solely on the fact that there are more of one color than the other. This criterion can be uniformly applied, no matter the proportion of red to blue balls. Therefore, any additional probabilistic information, such as a particular proportion of red to blue balls, will not significantly influence this prediction strategy (Conditions $1 \& 2$ ). However, when it is more desirable to predict a red ball while that outcome remains less probable due to a smaller proportion (Condition 3 ), the motivation to predict it conflicts with this simplest prediction strategy. It was hypothesized that in this condition, individuals would evaluate the probability of drawing a red ball more effortfully while making a prediction (e.g., Ditto \& Lopez, 1992; Ditto, et al., 1998). It was expected that this strategic change would be reflected as the increment of the proportion of the individuals who predicted a red ball, and this increment would also become more correlated and better calibrated to the actual proportion of red balls in the bag.

It is important to clarify the two issues related to the current experimental paradigm. First, there could be a similarity between the current experimental paradigm and the experimental paradigm used in repeated binary-choice studies. The repeated binary-choices were analyzed through aggregating multiple responses made by a single individual (Friedman \& Massaro, 1998; Gal, 1996; James \& Koehler, 2011; Newell \& Rakow, 2007; White \& Koehler, 2007). However, in the current research, the data were collected through aggregating a single response made by multiple individuals in order to identify a typical pattern of behavior, since a proportion becomes conceptually identical to a mean if binary-predictions are made independently by multiple individuals. A similar experimental paradigm to the present one has been frequently applied in research on the overconfidence phenomena in general knowledge questions (see Allwood \& Johansson, 2004; Dahl, Allwood, \& Hagberg, 2009; González-Vallejo, \& Bonham, 2007). Second, the question employed in the present experiments was specifically phrased as "Which color ball do you think will come out?" That is to say, the question asked each individual to guess an actual outcome rather than to choose a correct answer (e.g., "which color ball do you think is more probable or possible to come out?").

\section{Method}

\section{DATA COLLECTION FOR PROMPT 1}

A total of 541 participants (all adults, all US residents, both sexes, and all age groups; $M_{\text {age }}=35.8$ ) were recruited via online survey. These participants were asked to respond to the following prompt:

The bag has 100 balls. () balls are red, and () balls are blue. You have to pick one ball from the bag. Which color ball do you think will come out? (Check one): (a) a red ball, (b) a blue ball.
In the prompt, the proportions of red to blue balls was modified to have 9 conditions: 10:90, 20:80, 30:70, 40:60, 50:50, 60:40, 70:30, 80:20, and 90:10. Each of these nine conditions included approximately 60 participants. The dependent measure was the number of individuals who chose "(a) a red ball" for each proportion.

\section{DATA COLLECTION FOR PROMPT 2}

A total of 1.628 participants (all adults, all US residents, both sexes, and all age groups; $M_{\text {age }}=38.2$ ) were recruited via online survey. These participants were asked to respond to the prompt designed to motivate them to predict one outcome over the other. In order to psychologically trigger this motivation, the original prompt was modified such that predicting one outcome rather than the other potentially made an individual experience more positive affect (Conway \& Howell, 1989; Shedd \& Angelino, 1952; Weinstein, 1980). The specific idea for the modified prompt was borrowed from the method that was used in ancient India to determine the guilt of the accused, when there was neither witness nor evidence (Lyons, 2003; Sharan, 1978) ${ }^{1}$. This modified prompt is as follows:

The bag has 100 balls. () balls are red, and () balls are blue. You have to pick one ball from the bag, blind-folded. If a red ball comes out, you will receive $\$ 1,000,000$ and be released from prison. If a blue ball comes out, you will be tortured and killed. Now, you are picking up a ball. Which color ball do you think will come out? (Check one): (a) a red ball, (b) a blue ball.

In the prompt, the proportion of red to blue balls was modified to have 16 conditions: 5:95, 10:90, 15:85, 20:80, 25:75, 30:70, 40:60, 45:55, $47: 53,48: 52,49: 51,50: 50,60: 40,70: 30,80: 20$, and 90:10. Each of these 16 conditions included approximately 100 participants. The dependent measure was the number of individuals who chose "(a) a red ball" for each proportion.

For the analyses, the proportion of individuals who predicted a red ball was compared to each actual proportion of red balls using the graph based on the probability weighting function (Kahneman \& Tversky, 1979b; Tversky \& Kahneman, 1986).

All procedures conformed to the ethical principles of psychological research and were approved by the Internal Review Board (IRB), and informed consent was obtained from all participants ${ }^{2}$.

\section{Results and Discussion}

As shown in Figure 1, the results of the first prompt indicated that few individuals predicted a red ball when the actual proportion of red balls was below $50 \%$ (Condition 1). When the actual proportion of red to blue balls was 50:50, the prediction turned random (50\%). When the actual proportion of red balls was above $50 \%$, few individuals predicted a blue ball (Condition 2). This prediction strategy is numerically summarized as follows: $\left[\mathrm{P}(\mathrm{x}, \mathrm{y})_{\text {predictions }} \approx 1\right.$, when $\left.\mathrm{P}(\mathrm{x})_{\text {probability }}>\mathrm{P}(\mathrm{y})_{\text {probability }}\right]$, and $\left[\mathrm{P}(\mathrm{x}, \mathrm{y})_{\text {predictions }} \approx 0\right.$, when $\left.\mathrm{P}(\mathrm{x})_{\text {probability }}<\mathrm{P}(\mathrm{y})_{\text {probability }}\right]$. This formula indicates that individuals uniformly employed the single strategy for 


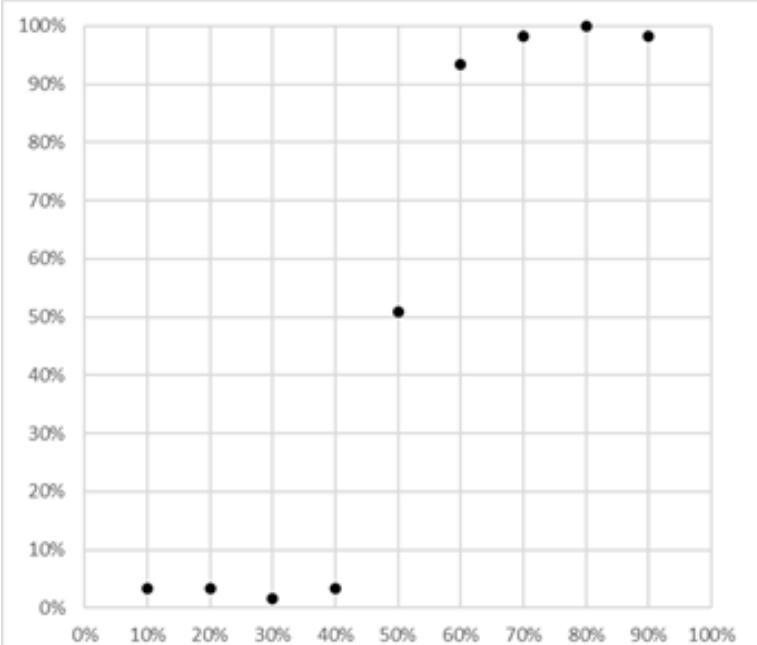

FIGURE 1.

The proportion of the individuals who predicted a red ball for each actual proportion of red balls in a bag (Conditions $1 \& 2$ ). Experimental results are plotted as dots. The horizontal axis indicates the actual proportion of the red balls in the bag. The vertical axis indicates the proportion of the individuals who predicted a red ball being drawn.

their predictions - predicting the more probable outcome - across the entire probability range.

The scatter plot shown in Figure 2 indicates how the second prompt changed the prediction pattern from the patterns observed with the first prompt. The second prompt was designed so that drawing a red ball supposedly led to a more desirable outcome. When the proportion of red balls ranged between $0 \%$ and $50 \%$ (Condition 3), the proportions of the individuals who predicted a red ball increased compared to those proportions observed with the first prompt (Condition 1). As seen in Figure 2, each of those proportions scattered near each actual proportion of red balls and increased as a function of it. When the proportion of red balls was at $50 \%$, the proportion of the individuals

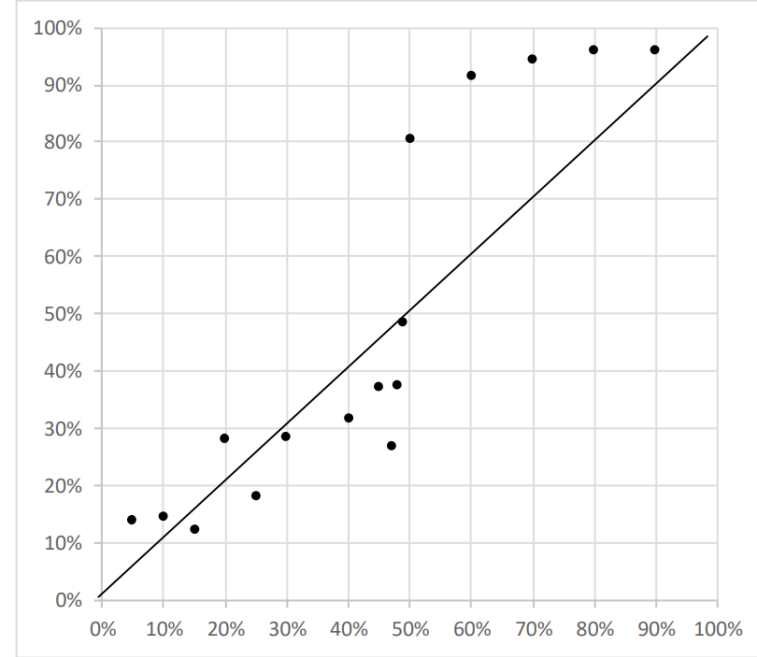

FIGURE 2.

The proportion of the individuals who predicted a red ball for each actual proportion of red balls in a bag when drawing a red ball was more desirable (Conditions $3 \& 4$ ). Experimental results are plotted as dots. The horizontal axis indicates the actual proportion of the red balls in the bag. The vertical axis indicates the proportion of the individuals who predicted a red ball being drawn.

who predicted a red ball dramatically surged (around $80 \%$ ). When the proportion of red balls ranged between $50 \%$ and $100 \%$, the prediction pattern observed with the second prompt (Condition 4) was almost identical to the prediction pattern observed with the first prompt (Condition 2). Overall, the inclusion of a desirable outcome in a binary prediction changed the pattern of predictions when a less probable outcome became more desirable (i.e., $0 \%-50 \%$; Condition 3).

In Figure 3, the prediction patterns represented by each regression line are compared among the four conditions. The left graph depicts the comparison between Condition 1 (red ball less probable) and Condition 3 (red ball less probable yet more desirable). The right graph depicts the comparison between Condition 2 (red ball more probable)

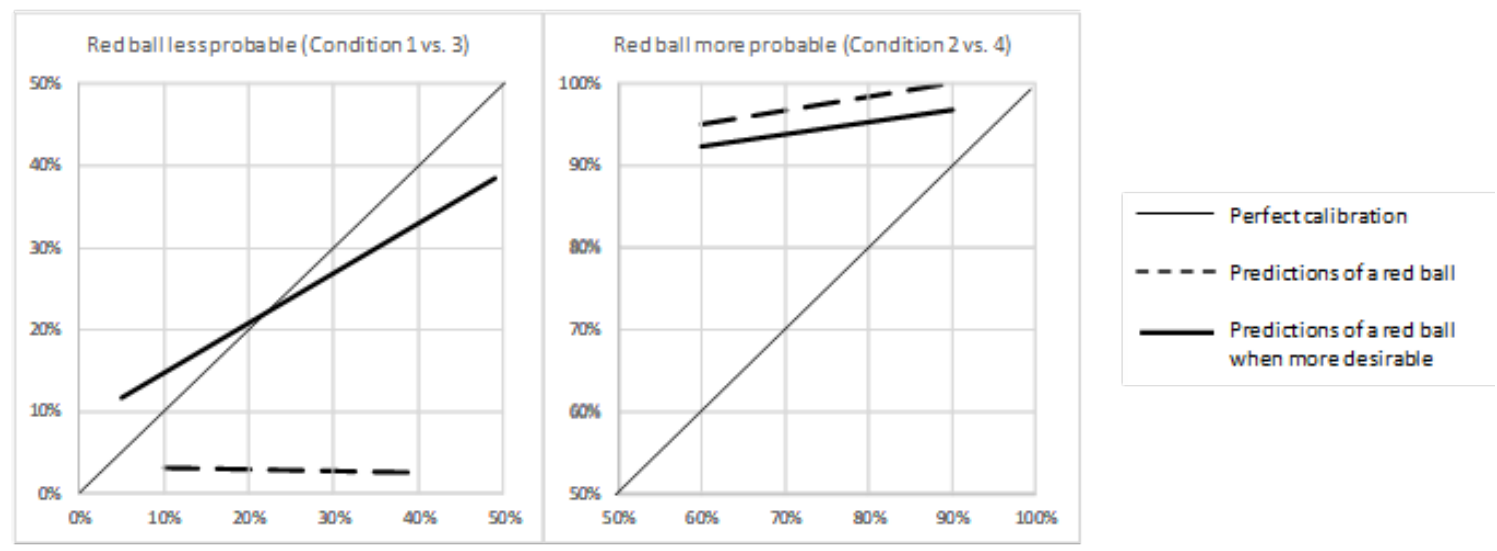

FIGURE 3.

Comparisons of the prediction patterns among the four conditions based on their linear regression lines. The horizontal axis indicates the actual proportion of red balls. The vertical axis indicates the proportion of the individuals who predicted a red ball being drawn. 
TABLE 1.

A Regression Coefficient, B, and Other Descriptive Statistics of the Four Conditions

\begin{tabular}{lccccccccc}
\hline & \multicolumn{3}{c}{ Red ball to a blue ball } & \multicolumn{4}{c}{$95 \%$ CI for $B$} & \multicolumn{3}{c}{$95 \%$ CI for Intercept } \\
& Probability & Desirability & $B$ & $p$ & Lower bound Upper bound & Intercept & Lower bound Upper bound \\
\hline Condition 1 & Less & & -.02 & .742 & -.21 & .17 & $3 \%$ & $-2 \%$ & $9 \%$ \\
Condition 3 & Less & More & .61 & .001 & .34 & .87 & $9 \%$ & $0 \%$ & $18 \%$ \\
Condition 2 & More & & .17 & .255 & -.29 & .62 & $85 \%$ & $51 \%$ & $119 \%$ \\
Condition 4 & More & More & .15 & .093 & -.06 & .36 & $84 \%$ & $68 \%$ & $99 \%$ \\
\hline
\end{tabular}

and Condition 4 (red ball more probable and more desirable). As seen in the left graph, the significant change occurred with the slope of the regression line (i.e., regression coefficient $\mathrm{B}$ ) between Condition 1 and Condition 3. This change indicates that, in Condition 3 , the proportion of individuals who predicted a red ball increased and, at the same time, this increase became more calibrated to the actual proportions of red balls. However, as seen in the right graph, the two prediction patterns of Conditions 2 and 4 did not indicate such a significant change.

Table 1 details the regression coefficient observed in each of the four conditions. In Condition 3, where the less probable outcome was more desirable, the proportion of individuals who predicted the less probable outcome became significantly correlated with the actual probability of this outcome $(B=.61, p=.001)$. Such a significant correlation between the proportion of predictions and outcome probability was not identified in any of the other three conditions. In addition, the regression coefficient (i.e., the slope of a regression line) of Condition 3 significantly increased from that of Condition 1, such that their 95\% CIs did not overlap, whereas their intercepts did not yield such a significant difference. Those two results indicated that the regression line of Condition 3 rose up closer-that is, calibrated significantly-to the diagonal line passing through each point of perfect calibration. On the other hand, such results were not observed between the regression lines of Conditions 2 and 4 . These results indicate that each actual proportion of red balls significantly influenced the proportion of individuals who predicted that a red ball would be drawn only when drawing a red ball was less probable yet more desirable. In the other three conditions, the prediction pattern was uniformly dictated by the simplest strategy-predicting the outcome that was more probable.

Overall, the probability of an outcome significantly influenced the proportion of predictions when the outcome was less probable yet more desirable. This phenomenon was interpreted as an indication that individuals more effortfully examined the probability of the outcome beyond the simplest criterion. This interpretation was based on how individuals made those predictions and, especially, what new aspect of the information they might have employed while making a prediction. When one outcome is more probable than the other, this information can be a sufficient criterion for a binary prediction to be made (Gigerenzer \& Goldstein, 1996; Goldstein \& Gigerenzer, 2002). However, when a less probable outcome becomes more desirable, this simplest criterion becomes more difficult to apply. Thus, such a condition could motivate individuals to seek out additional, new evidence or information (e.g., Ditto \& Lopez, 1992; Ditto, et al., 1998). In the current experiments, the only information available for each indi- vidual was the proportion between red and blue balls. For instance, in Condition 3, the only available information of the more desirable outcome was its probability, which was less than the probability of the other outcome. However, when an individual is motivated to predict the less probable outcome, for example, having $40 \%$ or $5 \%$ probability, these two probabilities would be perceived as significantly differentsuch that a probability of $40 \%$ would be seen as much more likely than a probability of $5 \%$. In all those regards, it was inferred that when making a binary prediction involving a less probable yet more desirable outcome, individuals evaluated the probability of the less probable outcome more effortfully, and this cognitive change could have produced the notably divergent prediction pattern observed in Condition 3.

\section{STUDY 2}

In Study 1, when individuals made a binary prediction wherein one outcome was less probable yet more desirable (Condition 3), the correlation and calibration between prediction proportion and outcome probability improved significantly. This phenomenon was interpreted as an indication that individuals evaluated the probability of the less probable outcome more effortfully because the simplest strategy - predicting the more probable outcome-was not applicable for predicting the desirable outcome. In Study 2, the concept of probability-matching was utilized to demonstrate the evidence that could support the validity of this interpretation. It has been observed that, when an individual makes several successive binary predictions, they also make predictions of a less probable outcome based on its actual probability. Namely, when one outcome is $10 \%$ probable (i.e., the other is $90 \%$ probable), an individual is likely to make a prediction of this outcome in roughly 10 out of 100 successive prediction attempts (Gal, 1996; James \& Koehler, 2011; Newell \& Rakow, 2007). This indicates that probability-matching is motivated by the probability information of the less probable outcome, which could also be an explanation for the different prediction pattern observed in Study 1, Condition 3. Consequently, it was hypothesized that the probability-matching motivation for a less probable outcome would significantly increase the number of individuals who predict a red ball in Condition 1. However, it was hypothesized that the same probability-matching motivation would not further increase the number of the individuals who predict a red ball in Condition 3. This is because the probability information (of the less probable outcome), on which probability-matching is also based, could be already integrated into the prediction made under Condition 3. Based on the conceptual frameworks explained so far, two experimental hypotheses for Study 2 were constructed. They can be summarized as follows: 
H1: In Condition 1, where drawing a red ball is less probable, the probability-matching motivation for the less probable outcome significantly increases the number of individuals who predict a red ball.

$\mathrm{H} 2$ : In Condition 3, where drawing a red ball is less probable yet more desirable, the same probability-matching motivation does not further increase the number of individuals who predict a red ball.

Study 2 consisted of two sub-experiments. In Experiment 1, the successive predictions based on the gambler's fallacy (see Lehrer, 2009, p. 66) was utilized to implement the probability-matching motivation to increase the numbers of individuals who predict a red ball under Condition 1 , where drawing a red ball is less probable. According to the gambler's fallacy, an individual often expects the probability of a less probable outcome to increase as the number of previous predictions increases. Namely, it was expected that more individuals would predict a red ball (less probable) after they had previously predicted a blue ball (more probable). In addition, it was identified how many predictions were necessary before the proportion of individuals who predict a red ball would significantly increase and become best calibrated to the actual proportion of red balls. This could identify the point at which the underlying probability, which the probability-matching was potentially based on, became best calibrated to the actual probability of a less probable outcome. Experiment 2 subsequently tested whether the same probability-matching motivation would also increase the proportion of individuals who predicted a red ball under Condition 3 , where drawing a red ball was less probable yet more desirable so that its probability information was assumed to be already integrated into the prediction.

\section{Experiment 1}

\section{METHOD}

A total of 420 participants (all adults, all US residents, both sexes, and all age groups; $M_{\text {age }}=37.1$ ) were recruited via online survey. The following prompt was employed as the device motivating the probability-matching in a binary prediction:

Imagine that 100 people are participating in the following task. The task is that a bag has 100 balls ("( ) balls are red", and "( ) balls are blue"), and each person (out of 100 people) picks one ball from the bag while blind-folded and identifies whether the color of the ball is "red" or "blue". After their turn, each person returns the ball to the bag, such that every time a selection is made, the bag always contains 100 balls with the same proportion of "red" and "blue" balls. The bag is sufficiently shuffled between each selection. Suppose that your four friends (Friend 1, Friend 2, Friend 3, \& Friend 4) are among the 100 people, and all 100 people (including your four friends) have just completed the task and identified their ball colors. Now consider the following:

- Which color ball do you "think" Friend 1 picked from the bag? (Check one): (a) a red ball, (b) a blue ball.

- Which color ball do you "think" Friend 2 picked from the bag? (Check one): (a) a red ball, (b) a blue ball.

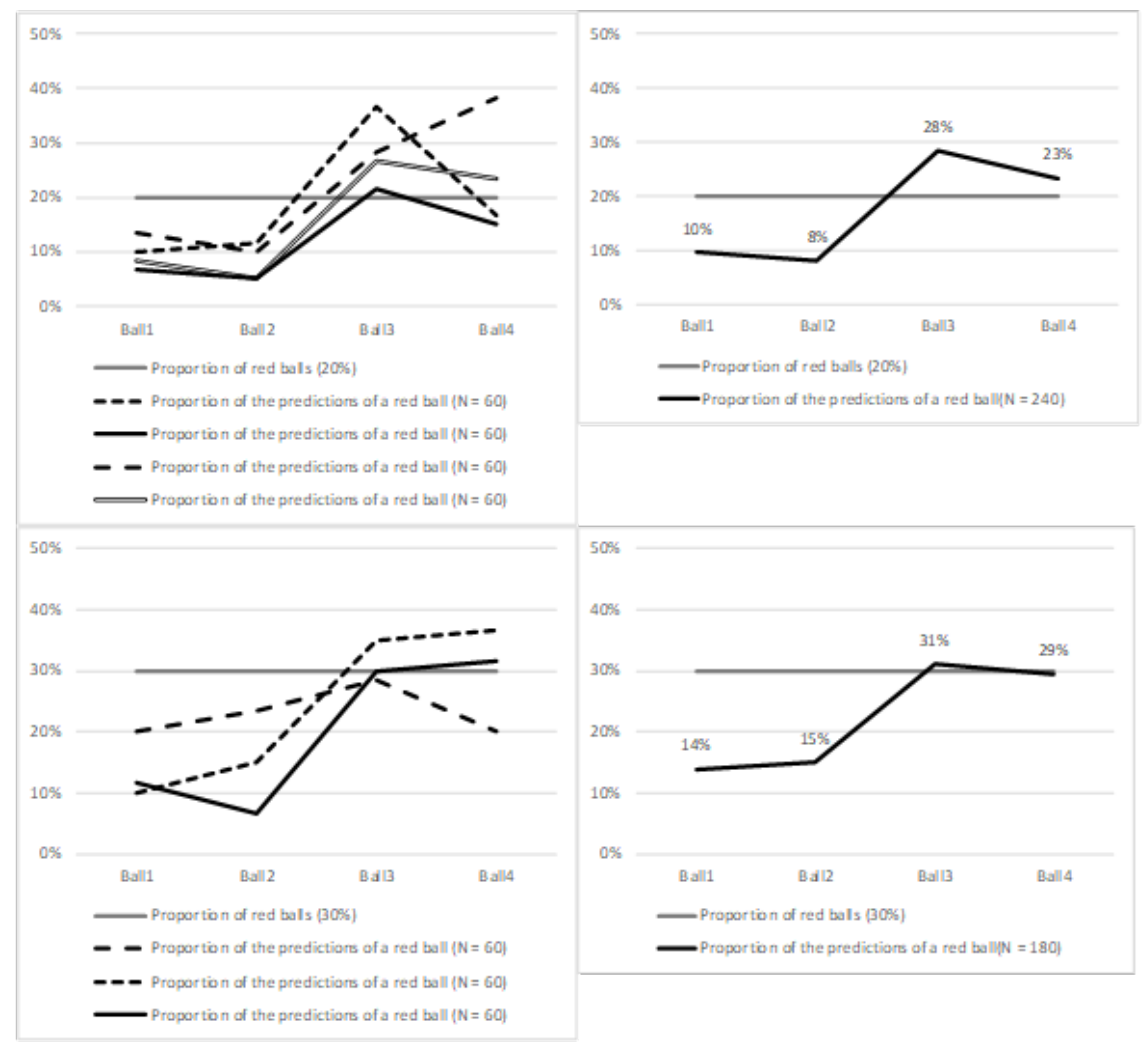

FIGURE 4.

Four successive predictions of a red ball with the proportion of 20:80 or 30:70 (red to blue balls). The number of individuals who predicted a red ball increased toward the actual proportion as the number of previous predictions increased. 
- Which color ball do you "think" Friend 3 picked from the bag? (Check one): (a) a red ball, (b) a blue ball.

- Which color ball do you "think" Friend 4 picked from the bag? (Check one): (a) a red ball, (b) a blue ball

Four sets of data collection (each set included 60 participants) were replicated for the 20:80 (red to blue balls) condition and three for the 30:70 (red to blue balls) condition. The dependent measure was the number of individuals who predicted a red ball being drawn for each condition.

All procedures conformed to the ethical principles of psychological research and were approved by the Internal Review Board (IRB), and informed consent was obtained from all participants ${ }^{3}$.

\section{RESULTS AND DISCUSSION}

As seen in the upper left graph of Figure 4, in the 20:80 condition, the predictions of the first and second ball did not constitute clear evidence implying that probability-matching had been employed in the prediction. These strategies were similar to the strategy observed in Study 1, Condition 1-predicting the more probable outcome. On the other hand, the proportion of the individuals who predicted a red ball increased toward the actual proportion with the third and fourth prediction. As seen in the upper right graph of Figure 4, with the third prediction, this proportion (28\%) somewhat surpassed the actual proportion (20\%). With the fourth prediction, this proportion $(23 \%)$ was almost identical to the actual one (20\%). As seen in the lower left graph of Figure 4, in the 30:70 condition, the first and second predictions did not show clear implications that probability-matching had been employed in the prediction. These strategies were also similar to the strategy observed in Study 1, Condition 1. On the other hand, as was also observed in the previous condition, the proportion of individuals who predicted a red ball increased toward the actual proportion with the third and fourth prediction. As seen in the lower right graph of Figure 4 , with the third prediction, this proportion (31\%) was almost identical to the actual proportion (30\%). With the fourth prediction, this proportion (29\%) was also almost identical to the actual one (30\%). Overall, in the 20:80 condition, the best calibration was observed in the fourth prediction (the upper right graph of Figure 4). In the 30:70 condition, both third and fourth predictions yielded similar levels of calibration in terms of their averages ( $31 \%$ vs. $29 \%$; the lower-right graph of Figure 4). However, in terms of the variability that each set of predictions yielded, the third prediction rendered better calibration than the fourth one: $2.3 \%$ (third prediction): $\mid\{[(30 \%-28 \%)+(30 \%-$ $35 \%)+(30 \%-30 \%)] / 3\} \mid<6.3 \%$ (a fourth ball $)=\mid\{[(30 \%-20 \%)+$ $(30 \%-37 \%)+(30 \%-32 \%)] / 3\} \mid$ (see the lower-left graph of Figure 4$)$.

Those results were interpreted as showing that while repeating the same prediction, individuals subconsciously expected that the probability of the less probable outcome had increased (i.e., the gambler's fallacy), and this changed expectation was reflected in the increment of the proportions of the individuals predicting a red ball with the third and fourth prediction. According to the results observed so far, when the proportion between red and blue balls was 20:80, the underlying probability, on which the probability matching was potentially based, was best calibrated to the actual proportion of red balls $(20 \%)$ at the fourth prediction. When the proportion was 30:70, this best calibration was observed at the third prediction. In Experiment 2, the same probability-matching motivation was implemented in Condition 3 , where predicting the less probable outcome was more desirable, and it was observed whether such significant increases also occurred.

\section{Experiment 2}

\section{METHOD}

A total of 360 participants (all adults, all US residents, both sexes, and all age groups; $M_{\text {age }}=34.4$ ) were recruited via online survey. Half of those participants $(n=180)$ were administered the prompt in which the proportion of red to blue balls was 20:80. The other half were administered the prompt in which the proportion was 30:70.

Both prompts were modified to include the clause previously used in Study 1, which indicated that drawing a red ball led to a more desirable outcome. All participants made four successive predictions in the same way as in Experiment 1. In the 20:80 proportion prompt, the original question of the fourth prediction was modified to "which color ball do you think you (previously Friend 4) picked from the bag?" In the 30:70 proportion prompt, the original question of the third prediction was modified to "which color ball do you think you (previously Friend 3) picked from the bag?" The dependent measure was the number of individuals who predicted a red ball for each condition. The results observed in Study 2, Experiment 2 were compared to the results observed in Study 1 and Study 2, Experiment 1.

All procedures conformed to the ethical principles of psychological research and were approved by the Internal Review Board (IRB), and informed consent was obtained from all participants ${ }^{4}$.

\section{RESULTS AND DISCUSSION}

The right graph of Figure 5 shows that with the proportion of 20:80, $36 \%$ of individuals predicted a red ball being drawn (by themselves) after three people had previously drawn a ball. With the proportion of $30: 70,37 \%$ of individuals predicted a red ball being drawn (by themselves), after two people had previously drawn. In Figure 5, these results, and also the results of Study 2, Experiment 1, are compared to the corresponding results observed in Study 1, where individuals made the same predictions yet without the probability-matching motivation. In the 20:80 proportion, no significant increment was observed in Study 2, Experiment 2: $N=265, \chi^{2}=1.39, p=.238$ (the right graph of Figure 5), whereas the increment observed in Study 2, Experiment 1 was significant: $N=300, \chi^{2}=12.31, p<.001$ (the left graph of Figure 5). In the 30:70 proportion, no significant increment was also observed in Study 2, Experiment 2: $N=267, \chi^{2}=1.87, p=.171$ (the right graph of Figure 5 ), whereas the increment observed in Study 2, Experiment 1 was also significant: $N=240, \chi^{2}=21.54, p<.001$ (the left graph of Figure 5).

These results constitute additional evidence for the inference that, when making a binary prediction wherein one outcome is less probable yet more desirable, individuals may integrate the probability information of the less probable outcome into their prediction to a greater 

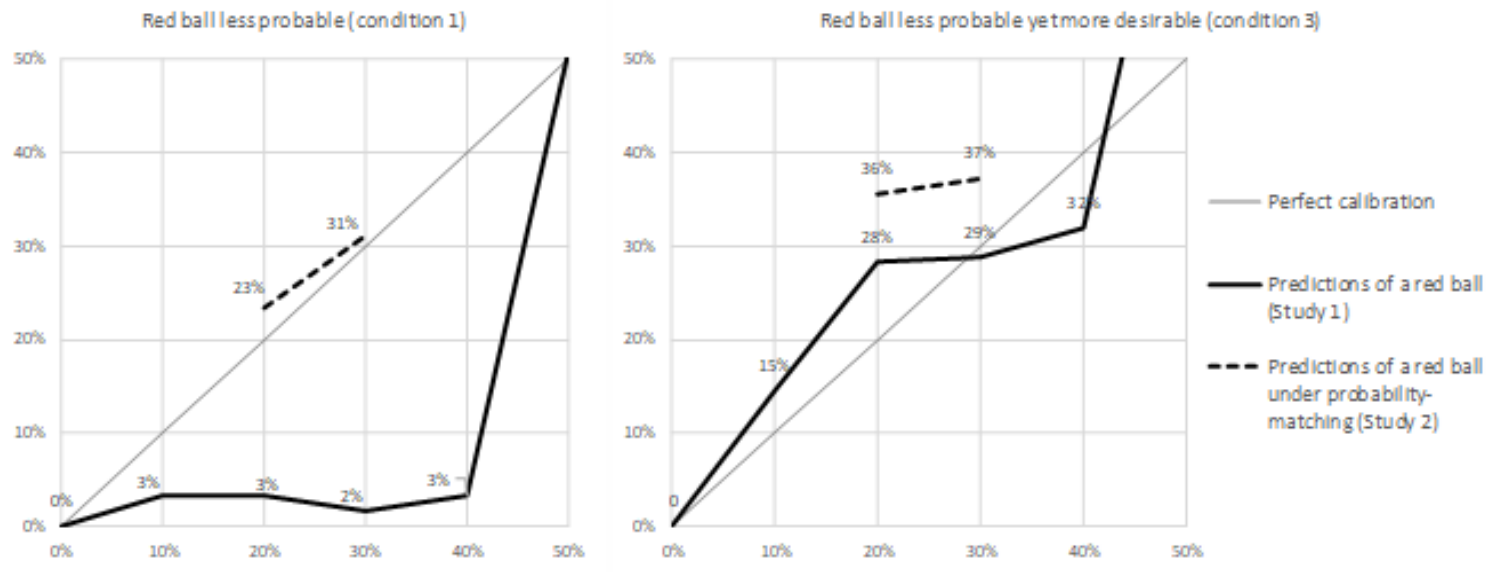

FIGURE 5.

The effect of probability-matching on the proportion of individuals who predicted a red ball with the proportion of 20:80 or 30:70 (red to blue balls) and under Condition 1 or Condition 3.

degree. In Study 1, the proportion of individuals who predicted a red ball significantly increased when it was both less probable and more desirable. If those individuals made those changes randomly - without using any probability information-the probability-matching motivation should have increased the proportion of those individuals (more or less) additively. This is because the probability-matching could have offered the probability information (of a less probable outcome), which had not been integrated into the original prediction. This indicates that, in the case of the 20:80 proportion, the probability-matching manipulation should have increased the proportion of individuals who predicted a red ball to approximately $51 \%$ (28\% in Study $1+23 \%$ in Study 2, Experiment 1), and, in the case of the $30: 70 \%$ proportion, to approximately $60 \%$ (29\% in Study $1+31 \%$ Study 2, Experiment 1$)$. However, the proportion of those predictions in both cases yielded much smaller and nonsignificant increases.

\section{GENERAL DISCUSSION}

For the current research, several concepts and theories were synthesized to formulate the rationales and hypotheses for conducting the experiments. While making a binary choice, individuals often utilize a simple criterion in a fast and frugal manner without further seeking out less accessible evidence or information (Gigerenzer \& Goldstein, 1996; Goldstein \& Gigerenzer, 2002; Dunn et al., 2016; Gold et al., 2015; Kool, et al., 2010). When this type of cognitive process is applied to the prediction of two future outcomes, individuals are likely to predict one outcome by using the simplest criterion, such as one outcome being more probable than the other. Cognitive effort is expended based on a trade-off between effort and reward, and if an individual does not foresee any resultant reward (at the expense of the effort), additional cognitive effort is unlikely to be exerted (Kool, et al., 2010; Kool \& Botvinick, 2014; Westbrook \& Braver, 2015). When predicting a desirable future outcome, individuals could gain affective reward (Bar-Hillel \& Budescu, 1995; Lench, 2009; Shepperd, et al., 2002), but predicting a desirable outcome also demands the cognitive process in which evidence or information must be searched and evaluated for this prediction to be possible (Krizan \& Windschitl, 2007). In a binary prediction having one outcome more desirable than the other, individuals are likely motivated to predict the more desirable outcome, however, if the more desirable outcome is less probable (and there is no other information available), (a) this condition motivates the individuals to predict the more desirable outcome; (b) this prediction must be made based on supportive information or evidence; (c) since the desirable outcome is less probable, the simplest strategy-predicting a more probable outcome-is more difficult to apply; and therefore, (d) additional effort could be expended to seek out some other evidence or information. Based on these assumptions, it was hypothesized that in such a condition, one new aspect of the information which might additionally be integrate into the prediction could be the stochastic nature of an outcome, namely, the expectation that a less probable outcome would occur by chance. The conducted experiments demonstrated several significant phenomena which potentially support this hypothesis.

In Study 1, individuals made a binary prediction based on the urn model where balls of two colors, red and blue, are in a bag with a specific proportion. While being aware of this proportion, individuals predicted which color ball would be drawn as a function of a different proportion between the two colors (i.e., from 10:90 or 5:95 to 90:10). The second prompt was modified such that drawing a red ball was supposed to be more desirable. In this way, the four conditions, differentiated by the probability and desirability of a particular outcome, were constructed for the analyses: Condition 1-predicting the less probable outcome; Condition 2-predicting the more probable outcome; Condition 3-predicting the less probable yet more desirable outcome; and Condition 4-predicting the more probable and more desirable outcome. The results in Condition 3 rendered a prediction pattern that was notably different from the pattern in the other three conditions, wherein the more probable outcome was uniformly predicted. Specifically, in Condition 3, the proportion of the individuals who predicted a red ball-the less probable yet more desirable outcome-increased significantly, and this increment became better calibrated and significantly correlated to the actual proportion of red balls. 
This phenomenon was interpreted as indicating that individuals evaluated the probability of the less probable outcome more effortfully because this information was potentially important and useful for predicting a desirable outcome.

Study 2 tested this interpretation by implementing the probabilitymatching motivation based on the gambler's fallacy. In the first experiment, individuals made four successive binary predictions between red and blue balls with the proportions of 20:80 or 30:70. After two successive predictions, the number of individuals who predicted a red ball-the less probable outcome-increased significantly toward the actual proportion of red balls. The second experiment implemented the same probabilitymatching motivation in Condition 3, where a red ball was still less probable $(20 \%$ or $30 \%)$ yet more desirable. In those conditions, no significant increments were observed with the proportion of the individuals who predicted a red ball. These results were interpreted as indicating that in those conditions, the individuals already evaluated the probability information of the less probable outcome in order to predict a desirable outcome, and that this was separate from the probability-matching motivation.

According to the results observed so far, individuals made a binary prediction in a fast and frugal manner by utilizing the simplest criterion of probability. As indicated in Figures 1 and Table 1, this prediction strategy was uniformly applied regardless of the specific proportion between the two colors. On the other hand, once a less probable outcome became more desirable, individuals seemingly regarded each specific probability of the less probable outcome as the important information to be evaluated. In other words, when a less probable outcome was more desirable, individuals might have significantly differentiated between the probabilities of the less probable outcome, and those differentiations were markedly reflected in the prediction pattern wherein the proportion of predictions and the actual outcome probability became significantly correlated and better calibrated (Figures $2 \& 3$ and Table 1). People are motivated to predict a more desirable outcome (Bar-Hillel \& Budescu, 1995; Lench, 2009), and seek out evidence or information for this prediction to be made (Krizan \& Windschitl, 2007). If any supportive evidence is not initially accessible, extra effort may be expended for further search. In such a condition, an individual could become more receptive cognitively or more responsive to any information potentially useful for such a prediction. Thus, as indicated in the current research, an individual would perceive an outcome having $45 \%$ probability to be significantly more likely than an outcome having $5 \%$ probability only when the individual was motivated to predict those outcomes. Other researchers have similarly suggested that some aspects of (objective) probability, such as its variability, could be perceived differently based on whether the probability was associated with a desirable outcome (e.g., Lench, Smallman, Darbor, \& Bench, 2014).

The current research demonstrated several phenomena which could support the speculation that individuals may process information in a more effortful manner if that information is useful for predicting a desirable outcome and gaining affective reward. Those phenomena were also in line with the ideas suggested by other researchers that making a prediction demands information (Krizan \& Windschitl, 2007), and self-serving motivation could trigger the effortful cognitive processing that is necessary for one to collect favorable information (Ditto \& Lopez, 1992; Ditto et al., 1998). In this regard, it can be suggested that self-serving motivation could activate (either or both) two separate functions of cognition. One is cognitive focus and the other could be cognitive effort. Extant theories of optimistic bias (e.g., planning fallacy) seem to focus more on how people selectively look for favorable information but likely ignore others (Gerrard et al., 1991; Gouveia \& Clarke, 2001; Kahneman \& Tversky, 1979a; Klar \& Giladi, 1997; Klar, et al., 1996; Marks \& Duval, 1991; Ross, et al., 1977). However, when favorable information is less accessible, extra effort must be expended for additional search. Further research could investigate how these two cognitive functions-focus and effort-work together and are influenced by different variables when an optimistic prediction is being made.

The research on cognitive effort seems to regard an emotional (i.e., intrinsic) reward, such as boosting self-esteem or feeling good about oneself, somewhat lightly as compared to biological (e.g., foods), cognitive (e.g., a correct answer), social (e.g., approval), and other types (e.g., monetary) of reward (Donovan, Hafsteinsson, \& Lorenzet, 2018; Lallement, et al., 2014; Kurzban, Duckworth, Kable, \& Myers, 2013; Milyavskaya, Inzlicht, Johnson, \& Larson, 2018; Schouppe, Demanet, Boehler, Ridderinkhof, \& Notebaert, 2014). In addition, cognitive effort is generally regarded as a manifestation of human executive function or general intelligence, so it has often been measured in the context of productive or improved performance (Kurzban, et al., 2013). However, it has been speculated that cognitive effort can also be expended in a self- serving manner, solely in service of intrinsic reward, such as positive affect, and the current research offered some evidence which potentially supports this speculation.

\section{FOOTNOTES}

1 "A white image of Dharma should be painted on one leaf and a black image of Adharma painted on another leaf. The two leaves should then be invoked with prayers and should be duly worshipped with perfumes, and white and black flowers etc. They should be enclosed in two balls made of earth and of equal size. Then the two balls should be placed unobserved in a fresh jar, one containing the painting of Dharma and the other that of Adharma. The accused should then be called upon to take out a ball from the jar and should repeat the word-"I am free from guilt may (the image or picture of) Dharma come to my hands." If he takes out Dharma he is honestly acquitted, if he takes out Adharma, he is held guilty." (Sharan, 1978, p. 165)

${ }^{2}$ No systematic exclusion criteria were applied in the current research. No preregistration was conducted. No additional conditions or studies either supporting or opposing the hypotheses were run for the current research.

${ }^{3}$ No systematic exclusion criteria were applied in the current research. No preregistration was conducted. No additional conditions or studies either supporting or opposing the hypotheses were run for the current research.

${ }^{4}$ No systematic exclusion criteria were applied in the current research. No preregistration was conducted. No additional conditions or studies either supporting or opposing the hypotheses were run for the current research. 


\section{REFERENCES}

Allwood, C. M., \& Johansson, M. (2004). Actor-Observer differences in realism in confidence and frequency judgments. Acta Psychologica, 117, 251-274. doi: 10.1016/j.actpsy.2004.06.006 سلس

Bar-Hillel, M., \& Budescu, D. (1995). The elusive wishful thinking effect. Thinking \& Reasoning, 1, 71-103. doi: 10.1080/13546789508256906

Brown, J. D. (1986). Evaluations of self and others: Selfenhancement biases in social judgments. Social Cognition, 4, 353-376. doi: 10.1521/soco.1986.4.4.353 1لسلس

Busemeyer, J. R., \& Townsend, J. T. (1993). Decision field theory: A dynamic-cognitive approach to decision making in an uncertain environment. Psychological Review, 100, 432-459. doi: 10.1037/0033-295X.100.3.432 الس السلسلس

Chevalier, N. (2018). Willing to think hard? The subjective value of cognitive effort in children. Child Development, 89, 1283-1295. doi: $10.1111 /$ cdev.12805 سلس

Conway, M., \& Howell, A. (1989). Ego-involvement leads to positive self-schema activation and to a positivity bias in information processing. Motivation and Emotion, 13, 159-177. doi:

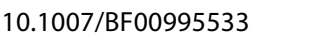

Dahl, M., Allwood, C. M., \& Hagberg, B. (2009). The realism in older people's confidence judgments of answers to general knowledge questions. Psychology and Aging, 24, 234-238. doi: 10.1037/a0014048

Ditto, P. H., \& Lopez, D. F. (1992). Motivated skepticism: Use of differential decision criteria for preferred and nonpreferred conclusions. Journal of Personality and Social Psychology, 63, 568-584. doi: 10.1037/0022-3514.63.4.568 الس الس

Ditto, P. H., Scepansky, J. A., Munro, G. D., Apanovitch, A. M., \& Lockhart, L. K. (1998). Motivated sensitivity to preferenceinconsistent information. Journal of Personality and Social Psychology, 75, 53-69. doi: 10.1037/0022-3514.75.1.53 سلسلسلس

Donovan, J. J., Hafsteinsson, L. G., \& Lorenzet, S. J. (2018). The interactive effects of achievement goals and task complexity on enjoyment, mental focus, and effort. Journal of Applied Social Psychology, 48, 136-149. doi: 10.1111/jasp.12498 المالسلسلس

Dunn, T. L., Lutes, D. C., \& Risko, E. F. (2016). Metacognitive evaluation in the avoidance of demand. Journal of Experimental Psychology: Human Perception and Performance, 42, 13721387. doi: $10.1037 / x h p 0000236$ 1لس

Efklides, A., Kourkoulou, A., Mitsiou, F., \& Ziliaskopoulou, D. (2006). Metacognitive knowledge of effort, personality factors, and mood state: Their relationships with effort- related metacognitive experiences. Metacognition and Learning, 1, 33-49. doi: 10.1007/s11409-006-6581-0

Fischbein, E., Nello, M. S. \& Marino, M. S. (1991). Factors affecting probabilistic judgements in children and adolescents. Educational Studies in Mathematics, 22, 523-549. doi: 10.1007/BF00312714 سلس

Fowers, B. J., Lyons, E. M., \& Montel, K. H. (1996). Positive marital illusions: Self- enhancement or relationship enhancement? Journal of Family Psychology, 10, 192-208. doi: 10.1037/0893-

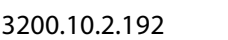

Friedman, D., \& Massaro, D. W. (1998). Understanding variability in binary and continuous choice. Psychonomic Bulletin \& Review, 5, 370-389. doi: 10.3758/BF03208814 الس

Gal, I. (1996). Understanding repeated simple choices. Thinking \& Reasoning, 2, 81-98. doi: 10.1080/135467896394573 السلسلس

Gerrard, M., Gibbons, F. X., \& Warner, T. D. (1991). Effects of reviewing risk-relevant behavior on perceived vulnerability among women marines. Health Psychology, 10, 173-179. doi: 10.1037/0278-6133.10.3.173 الس السلسلس

Gigerenzer, G., \& Goldstein, D. G. (1996). Reasoning the fast and frugal way: Models of bounded rationality. Psychological Review, 103, 650-659. doi: 10.1093/acprof:o

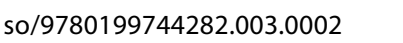

Gold, J. M., Kool, W., Botvinick, M. M., Hubzin, L., August, S., \& Waltz, J. A. (2015). Cognitive effort avoidance and detection in people with schizophrenia. Cognitive, Affective \& Behavioral Neuroscience, 15, 145-154. doi: 10.3758/s13415-014-0308-5 السلسلس

Goldstein, D. G., \& Gigerenzer, G. (2002). Models of ecological rationality: The recognition heuristic. Psychological Review, 109,

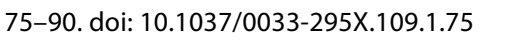

González-Vallejo, C., \& Bonham, A. (2007). Aligning confidence with accuracy: Revisiting the role of feedback. Acta Psychologica, 125, 221-239. doi: 10.1016/j.actpsy.2006.07.010 الس السلس

Gouveia, S. O., \& Clarke, V. (2001). Optimistic bias for negative and positive events. Health Education, 101, 228-234. doi:

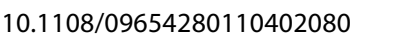

Harris, P. (1996). Sufficient grounds for optimism? The relationship between perceived controllability and optimistic bias. Journal of Social and Clinical Psychology, 15, 9-52. doi: 10.1521/ jscp.1996.15.1.9 المالسلس

Harris, P. \& Middleton, W. (1994). The illusion of control and optimism about health: On being less at risk but no more in control than others. British Journal of Social Psychology, 33, 369-386.

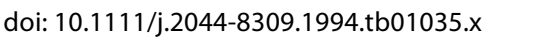

Hilbig, B. E., Michalkiewicz, M., Castela, M., Pohl, R. F., \& Erdfelder, E. (2015). Whatever the cost? Information integration in memory-based inferences depends on cognitive effort. Memory \&

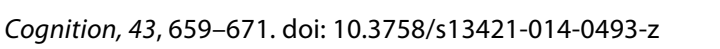
Hoorens, V (1993). Self-enhancement and superiority biases in social comparison. European Review of Social Psychology, 4, 113-139. doi: 10.1080/14792779343000040 الس الس

Hoorens, V. \& Buunk, B. P. (1993). Social comparison of health risks: Locus of control, the person-positivity bias, and unrealistic optimism. Journal of Applied Social Psychology, 23, 291-302. doi: 10.1111/j.1559-1816.1993.tb01088.x السلسلس

James, G., \& Koehler, D. J. (2011). Banking on a bad bet: Probability matching in risky choice is linked to expectation generation. Psychological Science, 22, 707-711. doi: 10.1177/0956797611407933 المالسلسلس

Jones, A. G., Langrall C. W., \& Mooney, E. S. (2007). Research in probability: Responding to classroom realities. In F. Lester 
(Ed.), Second handbook of research on mathematics teaching and learning (pp. 909-956). Greenwich, CT: Information Age Publishing.

Kahneman, D, \& Tversky, A. (1982). Variants of uncertainty. Cognition, 11, 143-157. doi: 10.1016/0010-0277(82)90023-3 السلسلس

Kahneman, D. \&Tversky, A. (1979a). Intuitive prediction: Biases and corrective procedures. TIMS Studies in Management Sciences, 12, 313-327. doi: 10.1017/CBO9780511809477.031 السلسلس

Kahneman, D. \& Tversky, A. (1979b). Prospect theory: An analysis of decision under risk. Econometrica, 47, 263-292. doi:

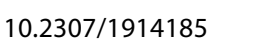

Klar, Y., \& Giladi, E. E. (1997). No one in my group can be below the group's average: A robust positivity bias in favor of anonymous peers. Journal of Personality and Social Psychology, 73, 885-901. doi: 10.1037/0022-3514.73.5.885 المالسلسلة

Klar, Y., Medding, A., \& Sarel, D. (1996). Nonunique invulnerability: Singular versus distributional probabilities and unrealistic optimism in comparative risk judgments. Organizational Behavior and Human Decision Processes, 67, 229-245. doi: 10.1006/obhd.1996.0076 البلسلس

Klein, C. T., \& Helweg-Larsen, M. (2002). Perceived control and the optimistic bias: A meta- analytic review. Psychology \& Health, 17, 437-446. doi: 10.1080/0887044022000004920 سلس

Kool, W., \& Botvinick, M. (2014). A labor/leisure tradeoff in cognitive control. Journal of Experimental Psychology: General, 143,

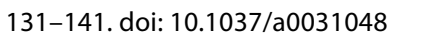

Kool, W., McGuire, J. T., Rosen, Z. B., \& Botvinick, M. M. (2010). Decision making and the avoidance of cognitive demand. Journal of Experimental Psychology: General, 139, 665- 682. doi:

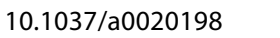

Krizan, Z., \& Windschitl, P. D. (2007). The influence of outcome desirability on optimism. Psychological Bulletin, 133, 95-121. doi: 10.1037/0033-2909.133.1.95 المالسلسل

Kurzban, R., Duckworth, A., Kable, J. W., \& Myers, J. (2013). An opportunity cost model of subjective effort and task performance. Behavioral and Brain Sciences, 36, 661-679. doi:

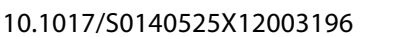

Lallement, J. H., Kuss, K., Trautner, P., Weber, B., Falk, A., \& Fliessbach, K. (2014). Effort increases sensitivity to reward and loss magnitude in the human brain. Social Cognitive and Affective Neuroscience, 9, 342-349. doi: 10.1093/scan/nss147 سلس

Langer, E. J., \& Roth, J. (1975). Heads I win, tails it's chance: The illusion of control as a function of the sequence of outcomes in a purely chance task. Journal of Personality and Social Psychology, 32, 951-955. doi: 10.1037/0022-3514.32.6.951 سلس

Lehrer, J. (2009). How we decide. New York: Houghton Mifflin Harcourt.

Lench, H. C. (2009). Automatic optimism: The affective basis of judgments about the likelihood of future events. Journal of Experimental Psychology: General, 138, 187-200. doi: 10.1037/ a0015380 الميلس

Lench, H. C., Smallman, R., Darbor, K. E., \& Bench, S. W. (2014).
Motivated perception of probabilistic information. Cognition,

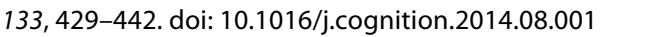

Loewenstein, G. F., Weber, E. U., Hsee, C. K., \& Welch, N. (2001). Risk as feelings. Psychological Bulletin, 127, 267-286. doi:

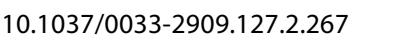

Lyons, L. (2003). The history of punishment. London: Amber Books. Marks, G., \& Duval, S. (1991). Availability of alternative positions and estimates of consensus. British Journal of Social Psychology, 30, 179-183. doi: 10.1111/j.2044- 8309.1991.tb00935.x السلسلس

McKenna, F. P. (1993). It won't happen to me: Unrealistic optimism or illusion of control? British Journal of Psychology, 84, 39-50. doi: 10.1111/j.2044-8295.1993.tb02461.x السلسلس

Newell, B. R., \& Rakow, T. (2007). The role of experience in decisions from description. Psychonomic Bulletin \& Review, 14, 1133-1139. doi: 10.3758/BF03193102 المالسلسلس

Milyavskaya, M., Inzlicht, M., Johnson, T., \& Larson, M. J. (2018). Reward sensitivity following boredom and cognitive effort: A high-powered neurophysiological investigation. Neuropsychologia, 123, 159-168. doi: 10.1016/j.neuropsychologia.2018.03.033 السلسلس

Nilsson, P. (2013). Challenges in seeing data as useful evidence in making predictions on the probability of a real-world phenomenon. Statistics Education Research Journal, 12, 71-83.

Otto, A. R., \& Daw, N. D. (2018). The opportunity cost of time modulates cognitive effort. Neuropsychologia 123, 92-105. doi:

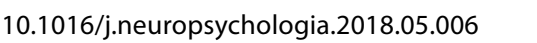

Piaget, J., \& Inhelder, B. (1975). The origin of the idea of chance in children. Oxford, England: W. W. Norton.

Ross, L., Greene, D., \& House, P. (1977). The false consensus effect: An egocentric bias in social perception and attribution processes. Journal of Experimental Social Psychology, 13, 279-301. doi: 10.1016/0022-1031(77)90049-X لسلسلس

Schmidt, L., Lebreton, M., Cléry-Melin, M., Daunizeau, J., \& Pessiglione, M. (2012). Neural mechanisms underlying motivation of mental versus physical effort. PLoS Biology, 10. doi: 10.1371/journal.pbio.1001266 السلسلس

Schouppe, N., Demanet, J., Boehler, C. N., Ridderinkhof, K. R., \& Notebaert, W. (2014). The role of the striatum in effort-based decision-making in the absence of reward. The Journal of Neuroscience, 34, 2148-2154. doi: 10.1523/

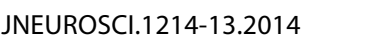

Sharan, M. K. (1978). Court procedure in ancient India. New Delhi: Abhinav Publications.

Shedd, C. L. \& Angelino, H. R. (1952). The effects of ego-involvement on learning. Proceedings of the Oklahoma Academy of Science, 33, 285-288. الفلسلس

Shepperd, J. A., Carroll, P, Grace, J, \& Terry, M. (2002). Exploring the causes of comparative optimism. Psychologica Belgica, 42,

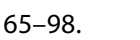

Sullivan-Toole, H., Dobryakova, E., DePasque, S., \& Tricomi, E. (2018). Reward circuitry activation reflects social preferences in the face of cognitive effort. Neuropsychologia, 123, 55-66. 
doi: 10.1016/j.neuropsychologia.2018.06.011 سلس Tversky, A. \& Kahneman, D. (1986). Rational choice and the framing of decisions. The Journal of Business, 59, 251-278. الس الس

Weinstein, N. D. (1980). Unrealistic optimism about future life events. Journal of Personality and Social Psychology, 39, 806820. doi: 10.1037/0022-3514.39.5.806 المالسلس

Weinstein, N. D. \& Klein, W. M. (1996). Unrealistic optimism: Present and future. Journal of Social and Clinical Psychology, 15, 1-8. doi: 10.1521/jscp.1996.15.1.1 المالسلسلة

Westbrook, A., \& Braver, T. (2015). Cognitive effort: A neuroeconomic approach. Cognitive, Affective, \& Behavioral Neuroscience, 15, 395-415. doi: 10.3758/s13415-015-0334-y سلس
White, C. M., \& Koehler, D. J. (2007). Choice strategies in multiple-cue probability learning. Journal of Experimental Psychology: Learning, Memory, and Cognition, 33, 757-768. doi: 10.1037/0278-7393.33.4.757 السلس الس

Williams, T. \& Clarke, V. A. (1997). Optimistic bias in beliefs about smoking. Australian Journal of Psychology, 49, 106-112. doi:

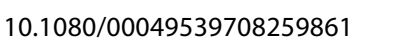

RECEIVED 04.07.2018 | ACCEPTED 22.05.2019 